\title{
Cross-species amplification of 36 cyprinid microsatellite loci in Phoxinus phoxinus (L.) and Scardinius erythrophthalmus (L.) Johannes Holmen ${ }^{* 1}$, Leif A Vøllestad ${ }^{1}$, Kjetill S Jakobsen ${ }^{1}$ and Craig R Primmer ${ }^{2}$
}

Address: ${ }^{1}$ Centre for Ecological and Evolutionary Synthesis (CEES), Department of Biology, University of Oslo, PO Box 1050 Blindern, N-0316 Oslo, Norway and 2Division of Genetics and Physiology, Department of Biology, 20014 University of Turku, Finland

Email: Johannes Holmen* - johannes.holmen@bio.uio.no; Leif A Vøllestad - asbjorn.vollestad@bio.uio.no; Kjetill S Jakobsen - k.s.jakobsen@bio.uio.no; Craig R Primmer - craig.primmer@utu.fi

* Corresponding author

Published: I4 December 2009

BMC Research Notes 2009, 2:248 doi:10.1 186/1756-0500-2-248

This article is available from: http://www.biomedcentral.com/l756-0500/2/248

(c) 2009 Holmen et al; licensee BioMed Central Ltd.

This is an Open Access article distributed under the terms of the Creative Commons Attribution License (http://creativecommons.org/licenses/by/2.0), which permits unrestricted use, distribution, and reproduction in any medium, provided the original work is properly cited.
Received: I August 2009

Accepted: 14 December 2009

\begin{abstract}
Background: To conduct phylogeographic or population genetic studies, an adequate number of DNA markers for the focal species are required. Due to severe unavailability of genotype markers of any kind for the species Eurasian minnow (Phoxinus phoxinus L.) and rudd (Scardinius erythrophthalmus $L$.), we set out to attempt cross-amplification of a set of microsatellite loci from related species.
\end{abstract}

Findings: We tested 36 cyprinid microsatellite loci for cross-species amplification in minnow and rudd. Fifteen species-locus combinations produced amplifications in minnow, seven being polymorphic, while 18 combinations amplified in rudd, nine of these being polymorphic.

Conclusions: The positive cross-species amplifications present potential contributions to the establishment of genetic marker sets for population genetics studies of the two focal species.

\section{Findings}

Microsatellites are widely used for population genetics purposes, especially when the scope of the study involves comparing closely related individuals. This is mainly due to their high mutation rates and to the potential of acquiring large amounts of data through relatively labour-thrifty multi-marker panel runs on capillary electrophoresis sequencers. However, utilization of microsatellites demands knowledge about their flanking sequences generated through library construction and/or PCR cloning approaches [1] to construct adequately sized annealing primer pairs. The flanking regions of microsatellites usually mutate at a much slower rate than the microsatellites themselves and will in many cases be identical across a species' range of distribution. They may even be conserved well enough through evolution to serve as primer templates for closely related species (see e.g. [2-4]).

The diverse family Cyprinidae, the most species-rich family of all vertebrates, has been paid only limited attention in population genetics studies. In the few studies available, the primary focus has been on a few species that have shared the status of being either commercially important or popular game fish; exemplified by studies on common carp (Cyprinus carpio L.) [5-7], goldfish (Carassius auratus L.) [8], European chub (Leuciscus cephalus L.) [9] and the genetic model species zebrafish (Danio rerio Hamilton) [10]. Therefore, for the great majority of cyprinids genetic 
markers are unavailable. In an earlier study, Holmen et al. [4] established a platform for optimization of microsatellite markers for six different cyprinids based on cross-species amplification of markers that initially were developed for D. rerio and central stoneroller (Campostoma anomalum Rafinesque). In this subsequent study, the platform was extended for two of the six species; Eurasian minnow (Phoxinus phoxinus L.) and rudd (Scardinius erythrophthalmus L.). We tested 36 microsatellite loci developed for the five cyprinid species fathead minnow (Pimephales promelas Rafinesque) [11], silver barb (Barbonymus gonionotus Bleeker) [12,13], common carp (Cyprinus carpio carpio L.) [14], Anaecypris hispanica (Steindachner) [15], and goldfish (Carassius auratus auratus L.) [16] for amplification of minnow and rudd DNA. Primer design incorporated the original primers with the addition of GTTT to the 5 ' end of one primer of each pair facilitating reasonably consistent adenylation of the 3' end of the forward primer [17] (see Additional file 1). We tested two samples of each focal species, yielding a total of 144 PCR reactions. To ascertain the polymorphism of a potential microsatellite locus, it is advisable to include more than only two samples of the focal species; however, we selected samples from populations situated far apart to increase the probability of polymorphism detection; minnow samples were from Norway and Spain, rudd from Norway and Italy.

We extracted genomic DNA from ethanol preserved fin tissue using a salt extraction protocol outlined by Aljanabi \& Martinez [18]. Further, we performed PCR reactions on MJ Research PTC-100/PTC-200, Techne or Biometra thermal cyclers. In the total volume of $10 \mu \mathrm{l}$, PCR reactions contained 20-100 ng genomic DNA, $20 \mu \mathrm{M}$ dNTP, plus 1 $\mu \mathrm{M}$ fluorescently labelled dUTPs (R110, R6G or TAMRA FdUTP; Applied Biosystems), $0.5 \mu \mathrm{M}$ of each primer, $1 \times$ BioTaq buffer (160 mM $\left(\mathrm{NH}_{4}\right)_{2} \mathrm{SO}_{4}, 670 \mathrm{mM}$ Tris- $\mathrm{HCl}$, $0.1 \%$ Tween-20; all buffer concentrations), $1.5 \mathrm{mM}$ $\mathrm{MgCl}_{2}$, and 0.1 units of BioTaq DNA polymerase (Bioline). PCR protocols were constructed with annealing temperatures and durations of incubations from published recommendations for the source species in mind. However, all PCR reactions were transformed to 'touchdown' procedures; starting with a relatively high annealing temperature, gradually decreasing it for each cycle and eventually keeping a fixed annealing temperature for a number of cycles towards the end. Details of the PCR protocols for all markers are given in Additional file 1 .

PCR products were pooled with a loading buffer and size standard mix (MegaBACE 10× Running buffer and MegaBACE ET400-R Size Standard, GE Healthcare, formerly Amersham Biosciences) and electrophoresed using a MegaBACE 1000 sequencer (GE Healthcare). Genotypes were scored using Genetic Profiler 1.5 (GE Healthcare). Scoring results were classified according to their amplification quality level, as outlined in Primmer \& Merilä [19]: 1: 1 or
2 alleles observed in a single individual, with little stuttering observed; 2: 1 or 2 alleles, moderate stutter; 3: 1 or 2 alleles, considerable stutter; 4: multiple bands and/or smear; 5: no amplification. Due to the possible confusion between true microsatellite alleles and other amplifications, bands having no trace of a weaker band one repeat below were included in category 4 , even when only one or two bands were observed. Note that no positive controls were used in these runs.

Thirty-three out of the total of 72 heterologous locus-species combinations resulted in products of amplification quality 3 or better (Table 1). Of these successful combinations, 15 (seven polymorphic) were recorded for minnow and 18 (nine polymorphic) for rudd. Interestingly, all eight successful amplifications with $C$. carpio loci were polymorphic for both target species, while only $24 \%$ of the remaining amplifying loci were polymorphic. Average amplification successes in Holmen et al. [4] were $40 \%$ in rudd and $49 \%$ in minnow, while the corresponding figures in the current study were $50 \%$ and $42 \%$, respectively. Some of the amplified loci were later optimized for population genetics studies in minnow (Holmen et al., in prep.), the selection being based on the number of alleles revealed in this study, amplification quality, and, in order to fit into an already half completed panel, the size range in which alleles appeared. Thus, only MFW1, MFW17, and GF11 have been further optimized and amplified in 1660 minnows from 72 sampling sites across Europe (Table 2). These three loci produced reasonably strong, unambiguous peaks after some optimization, and were included in the population studies. However, GF11 proved to exhibit very little variation; in fact it was monomorphic in 55 sampling sites, and thus the amount of genetic information from this locus was very limited. Within-population deviations from Hardy-Weinberg equilibrium were tested for using Genepop [20,21]. For these tests, only those 44 sampling sites that consisted of at least 17 individuals were included. MFW1 was polymorphic for all of these sampling sites, while MFW17 was polymorphic in all but one. For these two loci, none and one, respectively, of the samples deviated from HardyWeinberg equilibrium at the Bonferroni-adjusted 0.05 significance level. For GF11, only eleven samples were polymorphic, and out of those one was in Hardy-Weinberg disequilibrium. To specifically test for the presence of null alleles, ML-NullFreq [22] was employed. Using the Bonferroni-adjusted 0.05 significance level, one and four out of the 44 samples indicated the presence of null alleles in $M F W 1$ and MFW17, respectively. For GF11, six out of the eleven polymorphic sampling sites indicated the presence of null alleles, further emphasizing the limited value of this locus in population genetics studies. Unfortunately, further information of the tested loci is presently unavailable for S. erythrophthalmus. 
Table I: Details of cross-species amplification of 36 cyprinid microsatellites in P. phoxinus and S. erythrophthalmus

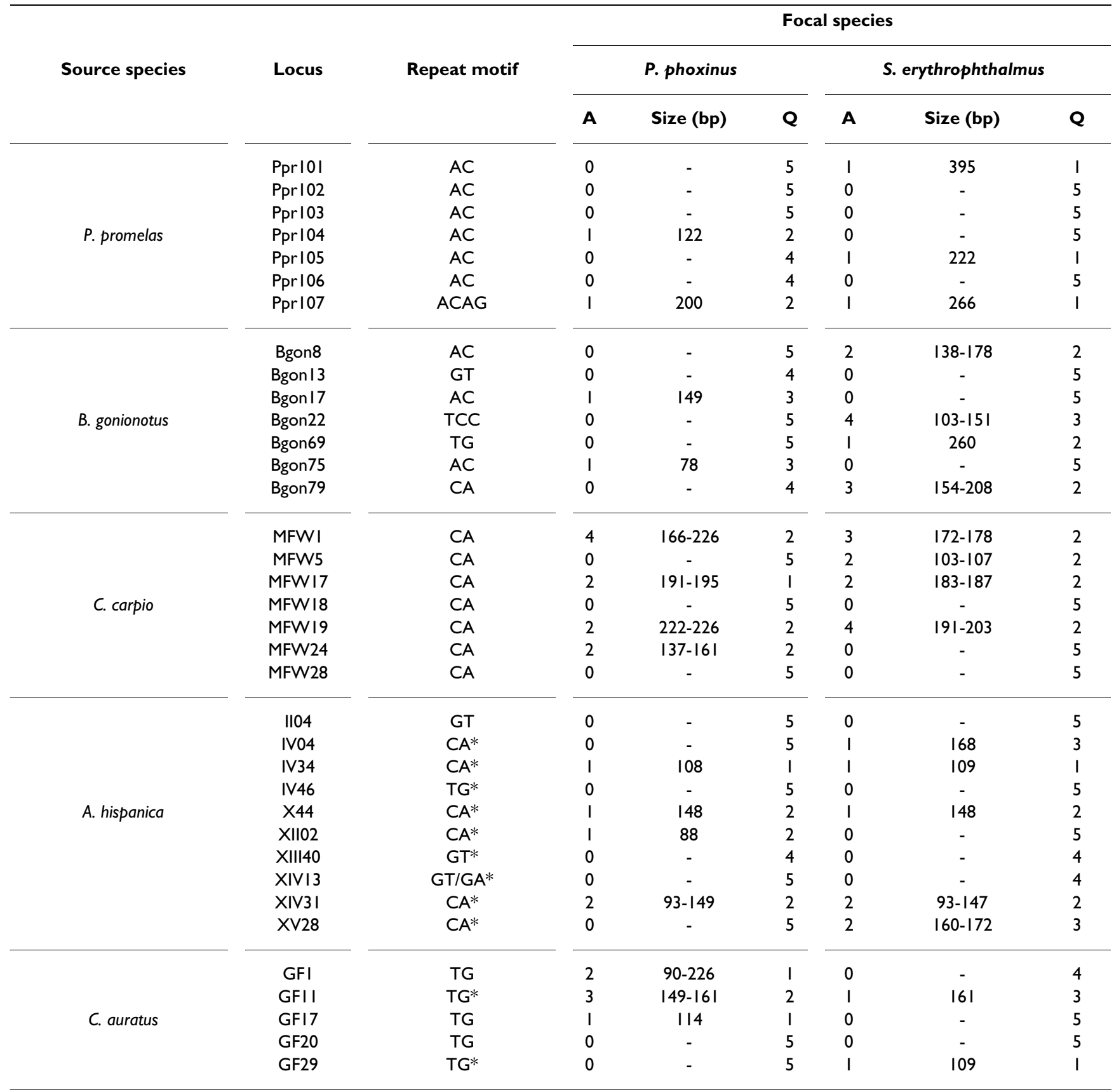

Number of alleles recorded (A), size (bp), and quality of the amplified product (Q: I, little stutter; 2, moderate stutter; 3, considerable stutter; 4, multiple bands or smear; 5, no amplification) are given. Asterisks denote non-continuous repeat motif sequences.

The likelihood that primer pairs developed for one species should amplify in a second species is higher the more closely related the two species are. On that general basis, one can assume the relative success rate among a number of cross-species amplification attempts. Cyprinidae taxonomy is rather complex. Although the family has traditionally been organized into several subfamilies, each comprising one or more lineages which in turn include a number of genera, and most lineages and genera are gen- erally accepted as being monophyletic, there is controversy regarding the monophyly of some subfamilies [23]. Thus, we had few obvious expectations regarding amplification successes in the present cross-species study. S. erythrophthalmus, $P$. phoxinus, $P$. promelas, and A. hispanica all belong to the subfamily Leuciscinae, but Hänfling \& Brandl [24] considered the genus Phoxinus to be a sister taxon to a Leuciscinae-Alburninae lineage. C. carpio, $C$. auratus, and B. gonionotus all belong to the Cyprininae 
Table 2: Population genetics parameters for the loci MFWI, MFWI 7 and GFII in P. phoxinus, based on amplifications in 1660 individuals from 72 sampling sites across Europe

\begin{tabular}{|c|c|c|c|c|c|}
\hline Locus & Number of alleles & $\mathbf{N}_{\mathrm{E}}$ & $\mathbf{H}_{\mathrm{E}}$ & $\mathbf{H}_{\mathbf{O}}$ & $\mathbf{F}_{\text {IS }}$ \\
\hline MFWI & 31 & 6.52 & 0.85 & 0.66 & -0.02 \\
\hline MFWI7 & 38 & 4.15 & 0.76 & 0.53 & 0.02 \\
\hline GFII & 3 & 1.08 & 0.07 & 0.05 & 0.26 \\
\hline
\end{tabular}

subfamily. P. promelas and A. hispanica loci were thus expected to amplify with a reasonably high rate in $S$. erythrophthalmus and slightly lower in P. phoxinus, and indeed, the success rates, defined as the proportions that produced peaks with amplification quality 3 or better, were $43 \%$ versus $29 \%$ and $50 \%$ versus $40 \%$ in favour of S. erythrophthalmus for the two source species, respectively. Loci from the Cyprininae subfamily were expected to produce a lower success rate in both target species. This was not the case, however, as amplification success ranged from $29 \%$ to $57 \%$. Notably, the number of loci examined is too low for any differences observed to be statistically significant. The results should therefore not be regarded as a contribution to the lineage discussion within Cyprinidae.

The present and our previous study [4] points out the usefulness of cross-species amplification of microsatellites in Cyprinidae to establish markers for population genetics studies. More specifically, the findings in these two papers have provided the authors with a useful set of markers for phylogeography and population genetics studies of the minnow and will hopefully contribute to fellow researchers' related work as well.

\section{Competing interests}

The authors declare that they have no competing interests.

\section{Authors' contributions}

JH carried out the molecular genetics laboratory work and drafted the manuscript. LAV conceived the study. KSJ helped design laboratory procedures. CRP had the major input to the design of the study. All authors read, contributed to and approved the final manuscript.

\section{Additional material}

\section{Additional file 1}

Primer sequences and PCR protocol details of all loci investigated Click here for file

[http://www.biomedcentral.com/content/supplementary/17560500-2-248-S1.DOC]

\section{Acknowledgements}

Italian rudd tissue and Spanish minnow tissue was kindly provided by $M$. Lorenzoni and J. A. Delgado Sáez, respectively. The study was financially supported by grants from the Norwegian Research Council, the Norwegian Directorate for Nature Management and the Finnish Academy.

\section{References}

I. Refseth UH, Fangan BM, Jakobsen KS: Hybridization capture of microsatellites directly from genomic DNA. Electrophoresis 1997, 18(9):1519-1523.

2. Primmer $\mathrm{CR}$, Møller AP, Ellegren $\mathrm{H}$ : A wide-range survey of cross-species microsatellite amplification in birds. Mol Ecol 1996, 5(3):365-378.

3. Tong J, Wang Z, Yu X, Wu Q, Chu KH: Cross-species amplification in silver carp and bighead carp with microsatellite primers of common carp. Mol Ecol Notes 2002, 2(3):245-247.

4. Holmen J, Vøllestad LA, Jakobsen KS, Primmer CR: Cross-species amplification of zebrafish and central stoneroller microsatellite loci in six other cyprinids. J Fish Biol 2005, 66(3):85I-859.

5. Desvignes JF, Laroche J, Durand JD, Bouvet Y: Genetic variability in reared stocks of common carp (Cyprinus carpio L.) based on allozymes and microsatellites. Aquaculture 200I, 194(34):29I-30I.

6. Fuchs H, Schlee P, Blusch J, Werner T, Stein H, Rottmann O: Phylogenetic studies in cyprinid species from central Europe by cytochrome b sequences of mitochondrial DNA. J Appl lchthyol 2000, I6(2):79-82.

7. Zhou JF, Wu QJ, Ye YZ, Tong JG: Genetic divergence between Cyprinus carpio carpio and Cyprinus carpio haematopterus as assessed by mitochondrial DNA analysis, with emphasis on origin of European domestic carp. Genetica 2003, I I 9(I):93-97.

8. Zhou L, Wang Y, Gui JF: Molecular analysis of silver crucian carp (Carassius auratus gibelio Bloch) clones by SCAR markers. Aquaculture 200I, 20I(3-4):219-228.

9. Larno V, Launey S, Devaux A, Laroche J: Isolation and characterization of microsatellite loci from chub Leuciscus cephalus (Pisces: Cyprinidae). Mol Ecol Notes 2005, 5(4):752-754.

10. Shimoda N, Knapik EW, Ziniti J, Sim C, Yamada E, Kaplan S, Jackson $D$, de Sauvage $F$, Jacob H, Fishman MC: Zebrafish genetic map with 2000 microsatellite markers. Genomics 1999, 58(3):219-232.

II. Ardren WR, Miller LM, Kime JA, Kvitrud MA: Microsatellite loci for fathead minnow (Pimephales promelas). Mol Ecol Notes 2002, 2(3):226-227.

12. Kamonrat W, McConnell SKJ, Cook DI: Polymorphic microsatellite loci from the southeast Asian cyprinid, Barbodes gonionotus (Bleeker). Mol Ecol Notes 2002, 2(2):89-90.

13. McConnell SKJ, Skibinski DOF, Mair GC: Microsatellite markers from a commercially important South-east Asian cyprinid, the silver barb (Barbodes gonionotus Bleeker). Mol Ecol Notes 200I, I(3): I35-136.

14. Crooijmans RPMA, Poel JJVd, Groenen MAM, Bierbooms VAF, Komen J: Microsatellite markers in common carp (Cyprinus carpio L.). Animal Genetics 1997, 28(2): 129-134.

15. Salgueiro P, Carvalho G, Collares-Pereira MJ, Coelho MM: Microsatellite analysis of genetic population structure of the endangered cyprinid Anaecypris hispanica in Portugal: implications for conservation. Biol Conserv 2003, 109(1):47-56.

16. Zheng W, Stacey NE, Coffin J, Strobeck C: Isolation and characterization of microsatellite loci in the goldfish Carassius auratus. Mol Ecol 1995, 4(6):79|-792.

17. Brownstein MJ, Carpten JD, Smith JR: Modulation of non-templated nucleotide addition by tag DNA polymerase: Primer modifications that facilitate genotyping. Biotechniques 1996, 20(6): 1004-1010.

18. Aljanabi SM, Martinez I: Universal and rapid salt-extraction of high quality genomic DNA for PCR-based techniques. Nucleic Acids Res 1997, 25(22):4692-4693.

19. Primmer CR, Merilä J: A low rate of cross-species microsatellite amplification success in Ranid frogs. Conserv Genet 2002, 3(4):445-449.

20. Raymond M, Rousset F: Genepop (Version-1.2) - PopulationGenetics Software for Exact Tests and Ecumenicism. J Hered 1995, 86(3):248-249. 
21. Rousset F: Genepop'007: a complete re-implementation of the Genepop software for Windows and Linux. Mol Ecol Resour 2008, 8(I): 103-106.

22. Kalinowski S, Taper M: Maximum likelihood estimation of the frequency of null alleles at microsatellite loci. Conserv Genet 2006, 7(6):99|-995.

23. Howes G]: Systematics and biogeography: an overview. In Cyprinid fishes - Systematics, biology and exploitation Edited by: Winfield IJ, Nelson JS. London: Chapman \& Hall; I991:I-33.

24. Hänfling B, Brandl R: Phylogenetics of European cyprinids: insights from allozymes. J Fish Biol 2000, 57(2):265-276.

Publish with Bio Med Central and every scientist can read your work free of charge

"BioMed Central will be the most significant development for disseminating the results of biomedical research in our lifetime. "

Sir Paul Nurse, Cancer Research UK

Your research papers will be:

- available free of charge to the entire biomedical community

- peer reviewed and published immediately upon acceptance

- cited in PubMed and archived on PubMed Central

- yours - you keep the copyright

Submit your manuscript here:

http://www.biomedcentral.com/info/publishing_adv.asp 